\title{
Experiment Research on Shading to Improve the Thermal Environment of Tents
}

\author{
Jingbo Liu ${ }^{1, \mathrm{a}}$, Yingni Jiang ${ }^{2}$, Zhengguo Gong $^{3}$ and Hao Yang ${ }^{4}$ \\ ${ }^{1,2,3,4}$ Architecture Engineering Department, Logistics University of PAP. Tianjin, China
}

\begin{abstract}
Different black agricultural shading-nets were erected on two 93 type military cotton tents to improve the thermal environment of tents in this paper. Indoor temperature, RH (relative air humidity) and interior wall temperature were tested. The experimental results show that shading-nets a effect on the improvement of thermal environment and 6 needled filters shading-net is better than 3 needled filters shading-net. The conclusion of this paper provides a basis for the improvement of the thermal environment and energy saving design of the tent.
\end{abstract}

\section{Introduction}

The tent is army camping equipment support, but there is a big flaw: thermal resistance and thermal inertia are small and the internal environment is hot, humid and poorly ventilated, seriously affect the rest of personnel[1]. There are a lot of researches on the improvement of tent thermal environment, but few scholars have applied the sun-shading technology to the tent[2-5]. In this work, the authers erected black shading-nets on tents, tested and analyzed the characteristics of the thermal parameters. The research on shading provides data reference and theoretical basis for upgrading the tents.

\section{Test object}

The experiment object is 93 type military cotton tent. Size: Long $4.4 \mathrm{~m}$, wide $4.6 \mathrm{~m}$, top high $2.57 \mathrm{~m}$, edge high $1.4 \mathrm{~m}[6]$. All the doors and windows were opened. two types of shading-nets were selected and erected on the top of the tent. One is "3 needled filters shading-net" (Net A), which has up to $75 \%$ shading rate and the tent under Net A were named
Tent A. The other is "6 needled filters shading-net" (Net B), which has up to $96 \%$ shading rate and the tent under Net A were named Tent B. The two shading-nets were erected about $1 \mathrm{~m}$ higher than the top of tents.

\section{Experiment scheme}

The experiment was done in Tianjin On September 8, 2015 at 8:30 16:00. That day the weather was from sunny to cloudy and the air temperature was from 20 degrees to 29 degrees. Tianjin is located at north part of northern China plain, has a sub-humid warm temperate continental monsoon four distinct seasons. Winter of Tianjin is cold and dry, while summer is hot and wet.

Mercurial thermometers, psychrometer and portable infrared thermometer were used to test indoor temperature, relative humidity and interior wall temperature. Twenty-five mercurial thermometers were put on 5 layers to test indoor air temperature and there were 5 thermometers in each layers representative position. The height of layers was $0.1 \mathrm{~m}, 0.5 \mathrm{~m}, 1.0 \mathrm{~m}$, $1.5 \mathrm{~m}, 2.0 \mathrm{~m}$, respectively. A psychrometer was put at tent center and another was put outside where there 
were no sunshine to test the different RHs. An infrared thermometer were used to test 6 interior wall temperature, these are north wall, east wall, west wall, top surface and ground surface. All the data were recorded every half an hour in the test.

\section{Experimental data analysis}

\subsection{Indoor air temperature}

Indoor temperature of Tent A is shown in Figure 1, indoor temperature of Tent B is shown in Figure 2.

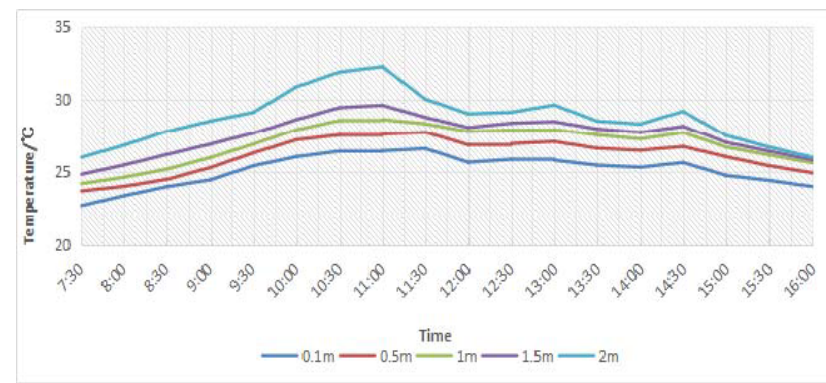

Figure 1. Indoor temperature of Tent A.

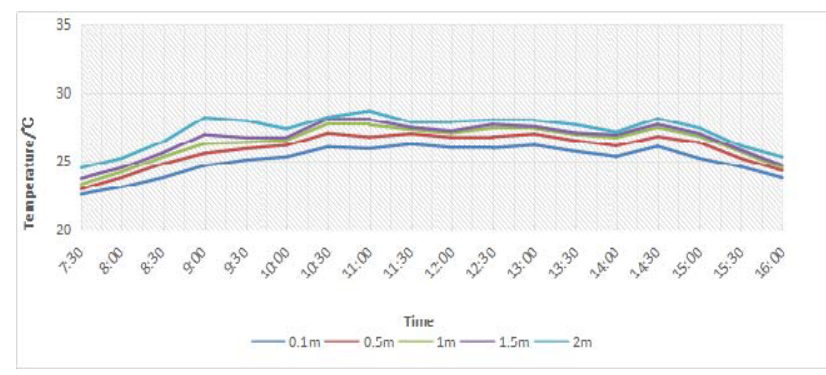

Figure 2. Indoor temperature of Tent B.

\subsubsection{Analysis}

It can be seen from Figure 1 that the indoor temperature rose at first, then dropped, and the highest temperature appears at 11:00. The reason is that the weather was clear before 11:00, the sunlight radiation transfer energy to Net A and tent, and the temperature was rising. After 11:00, it changed from sunny to cloudy, which caused the temperature to drop. While, there was little change in indoor temperature in Figure 2 , the temperature was rising at 7:30 9:00 while it was dropped at 14:30 16:00.

The $2 \mathrm{~m}$ layer was near to the top, its temperature rose faster than other layers. The highest temperature of Tent A was 32.2degrees, appeared at 11:00, 2.6 degrees higher than $1.5 \mathrm{~m}$ layer and 3.0 degrees higher than outside. While, the $2.0 \mathrm{~m}$ layer temperature of Tent $\mathrm{B}$ was lower than Tent $\mathrm{A}$. The reason is that the gaps of Net A is larger than Net B. and the sunlight reach the top of Tent A through Net A. More and more heat accumulated under the top, which cause the temperature to rise. The results shows that the shading effect of Net B is better than Net A, and there is little sunlight reach Tent B.

The temperature difference between the $2 \mathrm{~m}$ layer and 0.1 layer in Tent A is larger than Tent B. The maximum temperature difference was about 5.8degrees at 11:00. And the change of temperature was great in the entire test period. The influence of temperature cannot be ignored in reasonable breaks in Tent $\mathrm{A}$. The temperature difference between adjacent layers was about 0.5 degrees. What calls for special attention is that the temperature between $1.0 \mathrm{~m}$ and $1.5 \mathrm{~m}$ was closer to each other, especially at 11:30 14:30. The main reason is that there are 4 windows in tent at a same height, where there was the air convection between indoor and outside.

\subsubsection{Discussion}

The results indicated that the indoor temperature changes greatly between day and night. Because the small thermal resistance tarp, the indoor thermal environment is easy to be affected by different conditions: the top layer temperature was affected by the sunlight, the bottom layer was affected by the ground, the middle layer was affected air convection from windows. People in tent cannot have a good rest and sleep well.

Compared with Net A, Net B resists more sunlight and has a better shading effect, which result in the lower level of solar radiation and a more comfortable thermal environment. It is suggest that the improvement of thermal environment should be reasonable. When shading tent with nets, Net B can be selected as the best option.

The air in tent cannot have a strong convection with outside by the 4 same windows, which result in a stuffy environment. The present result suggests a means to improve the thermal environment that is to adjust a suitable size and height, especially in summer. 


\subsection{Air relative humidity}

Air relative humidity is shown in figure 3.

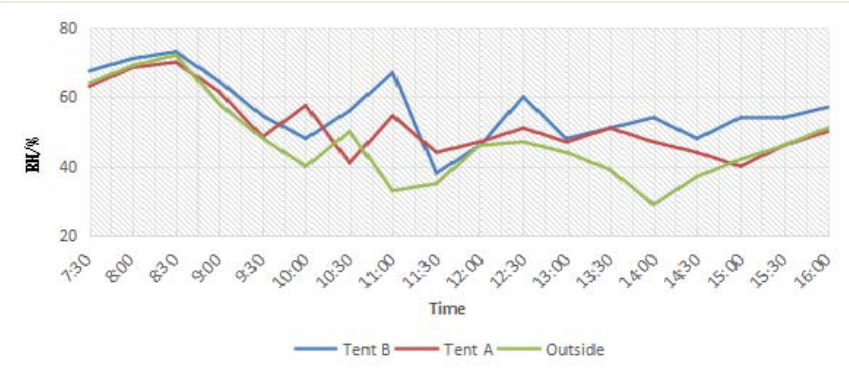

Figure 3. Air relative humidity.

\subsubsection{Analysis}

The result shows that the outside air RH was fit to the single peak curve, namely low at noon while high at morning and night. Show the opposite trend with the outside temperature. The main reason is the higher the drying temperature is, the lower $\mathrm{RH}$ value is at the same water holding capacity.

The RH of Tent A changed a lot in Figure 3. It was was high at 7:30 8:30, the reason is that the dew is easily to evaporate back into the atmosphere in the morning. The RH was nearly stable at 8:30 11:30, because of weaken air convection, the water holding capacity was stable. And the RH increase with the temperature dropping after 11:00.

The RH of Tent B was moderated so that it is always less than the variation of Tent $A$, and often much less. And because of weaken air convection, the indoor RH was higher than outside. The highest RH was $73 \%$,the lowest RH was $38 \%$ and the mean RH was $56 \%$.

There are some similarities of the curves above: low at noon while high at morning and night. Because of lower shading rate, Tent $\mathrm{A}$ is easier to receive solar radiation. Compared with Net $\mathrm{B}$, the RH of Net A is especially sensitive to temperature changes with the relatively constant of water vapor content.

\subsubsection{Discussion}

The results show a high RH in tent. The main factor was the ground, where the dew on the ground and moisture in the soil evaporated with the temperature rising. To reduce the RH in tent, trips is necessary to be lay on the ground.

The air convention is weaken. Adjust the height and size of windows can reduce the RH. Whereas the higher the ventilation rate, the lower the indoor relative humidity and the higher the warm respiratory comfort.

The indoor RH can be influenced by shading rate of nets. Net B can easily shade more sunlight, and Net B is a better choice of tent shading.

\subsection{Interior wall temperature}

The interior wall temperatures of the Tent A are shown in Figure 4. The interior wall temperatures of the Tent A are shown in Figure 5.

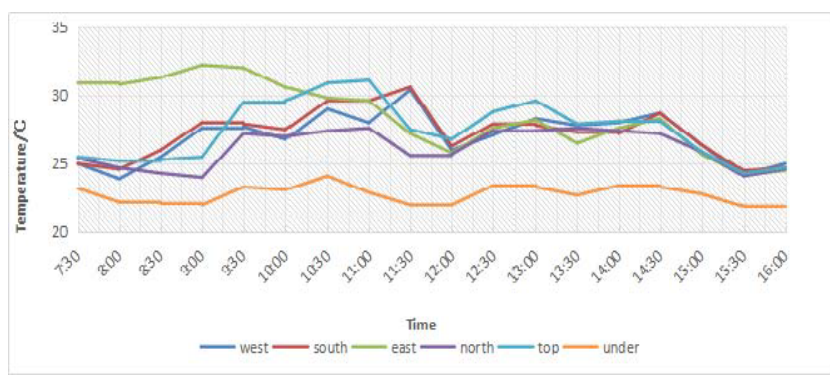

Figure 4. Interior wall temperatures of Tent A.

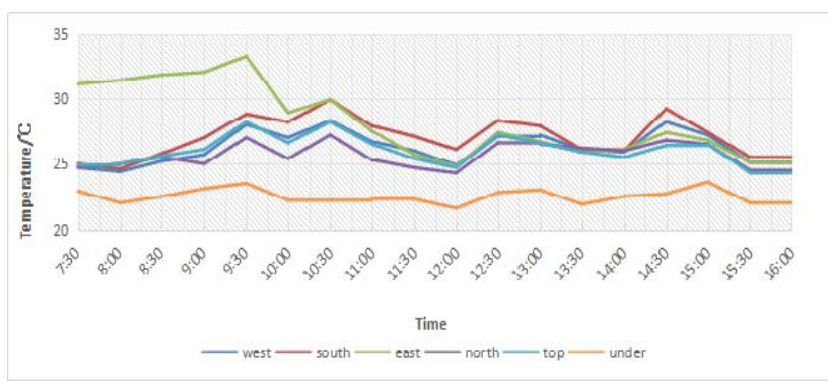

Figure 5. Interior wall temperatures of Tent B.

\subsubsection{Analysis}

The main reason for interior wall temperature rising was sunlight. You can see from Figure 3 and Figure 4 that the interior wall temperatures of Tent B is similar to Tent A. It's important to note, however, the curves of Tent $\mathrm{B}$ are more stable than Tent A.

The east wall temperature was obviously higher than other wall at 7:30 10:00 due to sunlight. And because of cloudy weather at afternoon, the west wall temperature was not as high as the east wall. The south wall temperature was higher than the north wall. The main reason for that is sunlight can reach the south 
wall and can not north. The ground temperature was stably 23 degrees. Because of larger gap of Net A, the roof temperature of Tent $\mathrm{A}$ is higher than Tent $\mathrm{B}$ at 9:30 11:00. After 14:30, the weather was cloudy and only a little sunlight shone on nets and tents, which make walls the near temperature.

\subsubsection{Discussion}

The walls of tent are greatly affected by the radiation of the sun. It shows that as the change of the solar azimuth, the same wall absorbed different solar radiation, the temperature changes. And as different walls absorbed different solar radiation at a same time, temperatures are different. The main reason is that the tent envelope thermal inertia is lower than fixed structures and can be easily affected by solar radiation.

The shading-nets can screen out much of the solar radiation and then the tent wall temperature dropped. Especially, Net B is rather better than Net A in shading.

The top of the tent can be shaded from the sun, but the east and west wall shading effect is limited. It is suggest that enhance the shading in east wall and the west wall and reduce the amount of radiation. Move the shading-net south in the northern area, which can reduce the amount of radiation in the south.

\section{Conclusion}

The tent thermal environment is greatly influenced by the outside, and the convection ability of indoor air and outside is weak. The erection of shading-net can effectively improve the indoor thermal environment. It is recommended that choosing the material with high shading rate as shading-net like Net B, and increasing the net area to the east, west and south, so that the radiation of sunlight could be reduced. Moreover, people can adjust the windows position and size to raise the capacity of air convection inside and outside the tent, and laying a cloth on the ground has the effect on damp-proof, reducing the relative humidity inside the tent.

\section{References}

1. S.Hu, Q.Meng, C.Wang. Experimental on the Improvement of the Thermal Environment of Tent. Journal of Logistical Engineering University: 02, 81-83+87(2007).

2. T.Wang, E.Long, Q.Yuan, H.Chen. Research on Thermal Insulation Effect of Double-roof Tent. Building Science: 12, 59-63(2010).

3. J.Ya, Y.Jin, S.Chen, P.Zeng, H,Wang. Improved Design of Disaster Relief Tent. Science \& Technology: 17, 13+80(2014).

4. R.Xu, G.Du. Development of Field Inflatable Medical Tent. Chinese Medical Equipment Journa: 14, 85-87(2013).

5. W.Wang, L.LIu, G.Liu. Research on Army Green Heat Reflective Coatings for Tents. Paint \& Coatings Industry: 9, 22-24(2008).

6. C.Su. Basic situation. Tianjin County Yearbook. (Tianjin Academy of Social Sciences Press, 35-36(2014)) 